\title{
Synthesis of Highly-loaded Holmium-165 Siloxane Particles for Brachytherapy of Brain Cancer and Injectability Evaluation in Healthy Pig
}

Marcon $\mathrm{L}^{1 * \#}$, Gehan $\mathrm{H}^{2 * \#}$, Khoshnevis $\mathbf{M}^{3}$, Marmuse $\mathrm{L}^{2}$, Carozzo $\mathrm{C}^{3}$, Louis $\mathrm{C}^{2}$, Ponce $\mathrm{F}^{3}$ and Tillement $\mathbf{O}^{1}$

${ }^{1}$ Institut Lumière Matière, UMR CNRS 5306, UCBL, Campus LyonTech - La Doua, Bâtiment Raulin, 10 rue Ada Byron, 69622 Villeurbanne, France ${ }^{2}$ Nano-H SAS, 2 place de l'Europe, 38070 Saint-Quentin Fallavier, France

${ }^{3}$ ICE (Interactions Cellules Environnement), UPSP 2016.A104, VetAgro Sup, Campus Vétérinaire de Lyon, 1 avenue Bourgelat, 69280, Marcy I'Etoile, France ${ }^{\#}$ Authors contributed equally

\begin{abstract}
Glioblastoma is the most invasive type of glial tumors, rapidly growing and commonly spreading into nearby brain tissue. Internal radiotherapy, also called brachytherapy, is an advanced cancer treatment where radioactive seeds are placed in or near the tumor itself, giving a high radiation dose to the tumor while reducing the radiation exposure in the surrounding healthy tissues. Among the available radioactive materials, ${ }^{166} \mathrm{Ho}$ emits high-energy $\beta$ radiation required for tumor destruction and low-energy $y$ radiation which can be used for quantitative SPECT imaging. In addition, Ho is a highly paramagnetic element and can therefore be visualized by MRI. In this context, we synthesized $400 \mathrm{~nm}$ particles via a sol-gel process in acidic conditions using holmium (III) oxide $\mathrm{Ho}_{2} \mathrm{O}_{3}$ as a nanostructured precursor. The objective was to design particles with a high ${ }^{165} \mathrm{Ho}$ content combined with an enhanced stability suitable for brachytherapy of brain cancer following neutron activation. A sol-gel process was chosen to make $\mathrm{Ho}_{2} \mathrm{O}_{3}$ soluble in aqueous media and to improve particle's colloidal stability. The resulting suspension showed enhanced colloidal stability in water, as evidenced by zeta potential and sedimentation rate measurements, combined with a high Ho content ( $28 \% \mathrm{w}: \mathrm{w})$. Injectability and preliminary acute toxicity of the suspension were assessed after stereotactic injection in the brain of healthy minipig. Computerized tomography (CT) imaging was performed to visualize the injection sites and to determine the holmium distribution. It turns out that our suspension provided high ${ }^{165} \mathrm{Ho}$ concentration to the site of action by way of stereotactic injection. This procedure allowed identifying suitable experimental conditions for future intratumoral injections of activated suspension.
\end{abstract}

Keywords: Holmium-165; Brachytherapy; Suspension; Minipig; Injectability; Glioblastoma

\section{Introduction}

Most common types of tumor treatments include surgery, chemotherapy and/or external radiotherapy. Radiation therapy or radiotherapy is a treatment using ionizing radiations (photons or charged particles) to damage DNA of malignant cells. Internal radiotherapy (also called brachytherapy) is an advanced cancer treatment. Radioactive seeds or sources are placed in or near the tumor using tube-like catheters, giving a high radiation dose to the tumor while reducing the radiation exposure in the surrounding healthy tissues [1]. Radioactive seeds may be produced under the shape of microspheres doped with $\beta$ emitting radionuclides; this technique is known as micro-brachytherapy [2].

Glioblastoma is the most invasive type of primary brain tumors, rapidly growing and commonly spreading into nearby brain tissue. Its incidence is $2-3$ per 100,000 adults per year in the US and Europe and approximately 13,000 cases are diagnosed each year in Europe. It shows the worst prognosis of all brain cancers because surgical resection of entire tumors is almost impossible [3]. Due to the high recurrence rate of glioblastoma, it is considered as incurable despite new medications such as Temozolomide and improved surgical techniques [4]. Consequently, many patients are eligible for micro-brachytherapy. The market for radiation therapy equipment is expected to reach US $\$ 8$ billion by 2020 due to rising incidence of cancer and increasing preference for non-surgical treatment options [5].

Recently, Gliasite $^{\bullet}$ (IsoRay Medical) has given a new impulse to brain tumors brachytherapy. This system is a form of intracavitary brachytherapy where a balloon catheter is introduced into the brain and inflated with a radioactive Iodine-125 solution [6]. Radiation is delivered locally to the surrounding brain tissues to treat tumors with greater accuracy, ensuring a high dose delivery. Unfortunately, this technique is controversial since it is not applicable for inoperable tumors, it shows a limited efficacy and induces higher costs for healthcare facilities [7].

In contrast, ${ }^{165} \mathrm{Ho}$ polysiloxane nanoparticles have been developed for applications in brachytherapy of liver malignancies [8]. Holmium shows several advantages over other elements such as ${ }^{90} \mathrm{Y}$ used in brachytherapy because: 1) it is a highly paramagnetic element suitable for MRI-guided selective administration, 2) after neutron activation, ${ }^{166} \mathrm{Ho}$ is a combined $\beta$ - and $\gamma$-emitter making the particles visible by Single Photon Emission Computed Tomography (SPECT) enabling nuclear imaging (useful for dosimetric calculations) relevant for personalized patient treatments [9]. Beta particles $\left(\mathrm{E}_{\max }=1.84\right.$ $\mathrm{MeV}$ ) exhibits radiotherapeutic properties appropriate for therapy. Additionally, the penetration range of ${ }^{166} \mathrm{Ho}$ into soft tissues is 1.23

*Corresponding authors: Lionel Marcon, Institut Lumière Matière, UMR CNRS 5306, UCBL, Campus LyonTech - La Doua, Bâtiment Raulin, 10 rue Ada Byron, 69622 Villeurbanne, France, Tel: 0034665105506; Fax: 33472431233; E-mail: lionel.marcon@univ-lyon1.fr

Helene Gehan, Nano-H SAS, 2 place de l'Europe, 38070 Saint-Quentin Fallavier France, Tel: 33663404380; E-mail: h.gehan@nano-h.com

Received: August 16, 2017; Accepted: August 24, 2017; Published: September 01, 2017

Citation: Marcon L, Gehan H, Khoshnevis M, Marmuse L, Carozzo C, et al. (2017) Synthesis of Highly-loaded Holmium-165 Siloxane Particles for Brachytherapy of Brain Cancer and Injectability Evaluation in Healthy Pig. J Nanomed Nanotechnol 8: 460. doi: 10.4172/2157-7439.1000460

Copyright: $\odot 2017$ Marcon L, et al. This is an open-access article distributed under the terms of the Creative Commons Attribution License, which permits unrestricted use, distribution, and reproduction in any medium, provided the original author and source are credited. 
$\mathrm{mm}$ on average with a maximum of $8.6 \mathrm{~mm}$, sufficient for microbrachytherapy of glioblastoma.

Similarly, holmium-166 poly(L-lactic acid) $\left({ }^{166} \mathrm{Ho}-\mathrm{PLLA}\right)$ microspheres have been developed at University Medical Center Utrecht (Utrecht, Netherlands) for quantitative multimodal in vivo imaging [10]. Other types of microparticles composed of lowerdensity polymers, including alginate [11] and chitosan [12] containing ${ }^{166} \mathrm{Ho}$, as well as nanosized carrier materials containing stable ${ }^{165} \mathrm{Ho}$ for subsequent neutron activation [13], have also been reported. However, most of these polymeric carrier materials cannot withstand long neutron irradiation times without degrading or aggregating. In this regard, Di Pasqua et al. designed mesoporous silica-based nanoparticles incorporating ${ }^{165} \mathrm{Ho}$ showing physicochemical stability before and after long reactor irradiation times [14]. Commercially available mesostructured silica nanoparticles were used to encapsulate a lipophilic acetylacetonate complex of ${ }^{165} \mathrm{Ho}$ in the pores. In addition, the use of "cold" isotope ${ }^{165} \mathrm{Ho}$ enables to overcome limitations of handling radioactivity (mostly characterization difficulties and necessity of radioprotection) during the synthesis.

On this basis, our strategy was to design particles with a high ${ }^{165} \mathrm{Ho}$ content combined with an enhanced stability suitable for brachytherapy of brain cancer. We synthesized $400 \mathrm{~nm}$ particles via a sol-gel process in acidic conditions using Holmium (III) oxide $\mathrm{Ho}_{2} \mathrm{O}_{3}$ as a nanostructured precursor. Such process was chosen to make $\mathrm{Ho}_{2} \mathrm{O}_{3}$ soluble in aqueous media and to improve particle's colloidal stability. In addition, this process is cost effective, scalable and allows for a fine control over thickness [15]. The resulting particles showed good colloidal stability in water, as evidenced by zeta potential and sedimentation rate measurements, combined with a high Ho content (28\% w:w).

Injectability and preliminary in vivo tolerability of the resulting ${ }^{165} \mathrm{Ho}$ siloxane suspension were assessed after stereotactic injection in the brain of healthy minipig. Pre- and post-operative computerized tomography (CT) imaging was performed to visualize the injection sites and to determine holmium distribution. This procedure allowed identifying suitable experimental conditions for future intratumoral injections of radioactive suspension.

\section{Materials and Methods}

\section{Chemicals}

All chemicals were reagent grade or higher and were used as received unless otherwise specified. Nanostructured holmium oxide $\mathrm{Ho}_{2} \mathrm{O}_{3}$ precursor was supplied by Nano-H SAS (Saint-Quentin Fallavier, France). N-[3-Trimethoxysilyl)propyl]ethylenediamine triacetic acid trisodium salt (Si-EDTA) $45 \%$ in water was obtained from Abcr. Acetic acid glacial was purchased from VWR Chemicals. Diethylene glycol $\geq 99 \%$ and polyethylene glycol 400 (PEG 400) were supplied by Sigma-Aldrich. Ethanol absolute anhydrous was obtained from Carlo Erba.

\section{Characterization of the nanostructured $\mathrm{Ho}_{2} \mathrm{O}_{3}$ precursor}

Nanostructured $\mathrm{Ho}_{2} \mathrm{O}_{3}$ precursor was characterized by X-ray diffractometry (XRD) using a Brüker D8 Advance diffractometer equipped with a Vantec high speed one dimensional detector. Analysis was performed by the Centre of diffractometry (CLEA - University Claude Bernard, Lyon, France). Holmium content was determined using Inductively Coupled Plasma - Mass (ICP-MS) spectrometry by analytical laboratory Antellis (Toulouse, France).

\section{Holmium-165 $\left({ }^{165} \mathrm{Ho}\right)$ siloxane particles synthesis}

Nanostructured $\mathrm{Ho}_{2} \mathrm{O}_{3}$ precursor $(0.397 \mathrm{~mol})$ was first slurried and refluxed in $1.5 \mathrm{~L}$ ethanol together with acetic acid $(0.262 \mathrm{~mol})$ and Si-EDTA $(0.05 \mathrm{~mol})$ for 20 hours. Mixture was then allowed to cool down to room temperature and transferred into $200 \mathrm{~mL}$ plastic centrifuge bottles (Fisher Scientific). Particles were washed in ethanol twice and water by centrifugation cycles (10 minutes at $4100 \mathrm{rpm})$ and resuspended in $160 \mathrm{~mL} \mathrm{mQ}$ water. Then, particle size was homogenized by stirring the suspension for 4 days at $30^{\circ} \mathrm{C}$.

\section{Characterization of the holmium-165 $\left({ }^{165} \mathrm{Ho}\right)$ siloxane particles}

Particle size was determined via Dynamic Light Scattering using a zetasizer Nano-ZS (Red Badge) Zen 3600 (Malvern Instruments) equipped with a $633 \mathrm{~nm}$ laser. ${ }^{165} \mathrm{Ho}$ siloxane suspension was diluted 200 times in diethylene glycol (DEG) to reach a mass concentration of approximately $2.5 \mathrm{~g} . \mathrm{L}^{-1}$. A total of 6 measurements were performed after 5 minutes equilibration time. Zeta potential was determined using the same apparatus coupled with an automatic titrator MPT-2 (Malvern Instruments). $\mathrm{pH}$ of the suspension was automatically adjusted between 7.0 and 12.5 using $\mathrm{NaOH} 0.1 \mathrm{M}$ and $\mathrm{HCl} 0.12 \mathrm{M}$. Measurements were performed at $25^{\circ} \mathrm{C}$ after a temperature homogenization time of 2 minutes.

Infra-red spectra were acquired using an IRAffinity 1 (Shimadzu Scientific Instruments) spectrophotometer controlled by LabSolutions IR software. One milliliter of suspension was dried in an oven at $80^{\circ} \mathrm{C}$ for 12 hours. Subsequent powder analysis was carried out by ATR technique using a single reflection diamond crystal on $\mathrm{ZnSe}$ plate. Density of the final ${ }^{165} \mathrm{Ho}$ siloxane suspension was measured in triplicate at $25^{\circ} \mathrm{C}$ by weighing $1 \mathrm{~mL}$ of suspension.

Dry matter corresponds to the mass of particles once the suspension has been entirely dried. Three glass vials were filled with $300 \mu \mathrm{L}$ suspension and left in an oven B170 (Nabertherm) at $300^{\circ} \mathrm{C}$ for 10 hours. Final value was given in g. $\mathrm{L}^{-1}$. Viscosity was measured at $25^{\circ} \mathrm{C}$ using a SV-10 vibro-viscometer (A\&D, Japan) by detecting the electric current necessary to resonate two sensor plates in a sample fluid.

Sedimentation rate was determined using a method based on erythrocyte sedimentation rate (ESR). ESR is the rate at which red blood cells sediment in one hour. Graduated glass sedimentation tubes and frame with cross-lever bar were obtained from Dehag (Germany). Tubes were filled with $700 \mu \mathrm{L}$ suspension until the zero mark. Suspension was then allowed to stand in the tube placed vertically for one hour. Under gravity, particles tend to settle out from the solvent. The rate at which they settle is measured as the number of graduations (millimeter) of clear solvent present at the top of the tube after one hour (mm per hour or \%). Each measurement was made in triplicate.

\section{Animal and surgical procedure}

A four months Yucatan minipig (19.3 kgs, INRA Saint-Gilles, France) was left 10 days for acclimatization. Minipig was premedicated with an intramuscular injection of atropine sulfate and azaperone. After 20 minutes, anesthesia was administered intramuscularly with Zoletil $^{\circ} 100$ (Tiletamine + Zolazepam). Sedation was achieved by a continuous inhalation of Isoflurane $2 \%$. Pre-operative analgesia consisting of morphine hydrochloride (Aguettant ${ }^{\star}$ ) was injected. Head of the pig was subsequently fixed in a Large Animal Stereotactic Frame (Stereotaxic Instruments, RWD 68901). Incision site was disinfected with a povidone-iodine solution. A $7 \mathrm{~cm}$ longitudinal skin incision was 
made on the midline of skull, $2 \mathrm{~cm}$ in cranial part of occipital crest. Periosteum was abducted to clear the skull bone and the intersections. Six holes (diameter $4 \mathrm{~mm}$ ) were drilled in the skull on both left and right hemispheres. Syringe pusher KDS Legato 130 (KD Scientific, USA) was mounted on the stereotactic system. In parallel, ${ }^{165} \mathrm{Ho}$ siloxane suspension was vortexed for 1 minute and then loaded into a $1 \mathrm{~mL}$ syringe (BD Plastipak) connected to either a $25 \mathrm{G} \times 40 \mathrm{~mm}$ cannula (Magic Needle) or a $25 \mathrm{G} \times 50 \mathrm{~mm}$ lumbar puncture needle (BD Neonatal) pre-wetted with PEG 400 surfactant. The syringeneedle combination was mounted on the syringe pusher. A total of six injections were performed.

Three injections were made in the right hemisphere using $25 \mathrm{G}$ cannula as follows: 1) $3 \mu \mathrm{L}$ of suspension at an injection rate of 100 $\mu \mathrm{L} / \mathrm{min}$ (injection depth: $10.8 \mathrm{~mm}$ from the surface of the skull), 2) 5 $\mu \mathrm{L}$ at $100 \mu \mathrm{L} / \mathrm{min}$ (injection depth: $11.3 \mathrm{~mm})$, 3) $10 \mu \mathrm{L}(2 \times 5 \mu \mathrm{L}$ with 2 minutes idle time in between) at $100 \mu \mathrm{L} / \mathrm{min}$ (injection depth: 13.4 $\mathrm{mm}$ ). Then, three injections were made in the left hemisphere using 25G needle as follows: 1) $3 \mu \mathrm{L}$ at $100 \mu \mathrm{L} / \mathrm{min}$ (injection depth: 10.8 $\mathrm{mm}$ ), 2) $5 \mu \mathrm{L}$ at $100 \mu \mathrm{L} / \mathrm{min}$ (injection depth: $11.3 \mathrm{~mm}$ ), 3) $10 \mu \mathrm{L} \mathrm{(2}$ $\times 5 \mu \mathrm{L}$ with 2 minutes idle time in between) at $100 \mu \mathrm{L} / \mathrm{min}$ (injection depth: $13.4 \mathrm{~mm}$ ). Cannula and needle were gently withdrawn in about 45 seconds from the brain two minutes after the injections.

Post-operative CT scans of the brain were performed by Voxcan (Marcy l'Etoile, France) using a CT-Scan GE BrightSpeed 16 (GE Healthcare) to determine the location of injection sites and observe the distribution of cold holmium. Three-dimensional volumes were reconstructed using OsririX and RadiAnt softwares. Then, $30 \mathrm{ml}$ of pentobarbital (Dolethal) were administered intracardially, causing a painless and immediate death.

\section{Results and Discussion}

First, commercial nanostructured $\mathrm{Ho}_{2} \mathrm{O}_{3}$ precursor was analyzed using X-Ray diffractometry (XRD), exhibiting a crystallite size of $60 \pm$ $15 \mathrm{~nm}$. Inductively Coupled Plasma - Mass (ICP-MS) measurements showed an high Holmium content of $85 \pm 3 \%$ w:w. Submicronic particles were then obtained using a sol-gel process. Reaction consisted in mixing the $\mathrm{Ho}_{2} \mathrm{O}_{3}$ precursor in ethanol in presence of acetic acid and Si-EDTA silane ( $2 \%$ massic equivalent $\mathrm{SiO}_{2}$ ) under reflux (Figure 1). Resulting particles were washed successively with ethanol and water, and then redispersed in $\mathrm{mQ}$ water.

Particle size was determined by Dynamic Light Scattering; suspension was diluted in a polyol solvent of moderate viscosity, i.e. diethylene glycol (DEG, $37.5 \mathrm{mPa} . s$ at $25^{\circ} \mathrm{C}$ ), to limit sedimentation following dilution. The particles exhibited a hydrodynamic diameter of $400 \pm 150 \mathrm{~nm}$ (Figure 2).

The transmission FTIR spectrum of the particles is displayed in Figure 3. The broad band around $3400 \mathrm{~cm}^{-1} \mathrm{can}$ be assigned to $-\mathrm{OH}$ and
$-\mathrm{COOH}$ stretching vibrations. The peak at $1558 \mathrm{~cm}^{-1}$ is due to $-\mathrm{COO}$ vibrations. Finally, the presence of a peak at $1412 \mathrm{~cm}^{-1}$ can be attributed to $\mathrm{C}-\mathrm{O}$ bonds. Taken together, the presence of these peaks indicates the successful attachment of the Si-EDTA silane to the nanostructured $\mathrm{Ho}_{2} \mathrm{O}_{3}$ precursor.

The Ho content, as measured by ICP, was $28 \pm 3 \% \mathrm{w}$ : w, which is superior to the value of $17 \pm 0.5 \%$ obtained by the Ho-loaded poly(Llactic acid) microspheres produced by the University Medical Center (Utrecht, Netherlands) [10]. This value will potentially enable the delivery of a high radioactive dose to tumor cells. In addition, density $(1.42 \pm 0.04)$ as well as dry matter $\left(550 \pm 50\right.$ g. $\left.\mathrm{L}^{-1}\right)$ high values confirmed the visual assessment that the suspension is highly concentrated. Viscosity is around 5-9 $\times 10^{-3} \mathrm{~Pa}$.s which is comprised between the viscosity of blood $\left(3-4 \times 10^{-3} \mathrm{~Pa} . \mathrm{s}\right)$ and ethylene glycol $\left(16 \times 10^{-3} \mathrm{~Pa} . \mathrm{s}\right)$ [16]. The rheology of a particle suspension is a complex function of its physical properties since the key factors are particle volume fraction, particle shape, inter-particle forces and the spatial arrangement of particles [17]. Unlike parenteral suspensions, the formulation of stable and injectable suspensions for glioblastoma radiotherapy involves use of high solid content and/or increased viscosity to stabilize the formulation (i.e. to enhance colloidal stability).

To assess colloidal stability, we first measured the effect of $\mathrm{pH}$ on the zeta potential in a $\mathrm{pH}$ range between 7.0 and 12.5 (Figure 4). Under physiological conditions ( $\mathrm{pH} 6-8$ ), zeta potential is around $30 \mathrm{mV}$ and decreases from 9.5 onward. It proves that inter-particle forces are greater than attractive forces among particles. Indeed, it is generally considered that particles with zeta potentials higher than $30 \mathrm{mV}$ or lower than $-30 \mathrm{mV}$ are stable in solution $[18,19]$. The high positive value is mainly imparted from the predominant presence of holmium oxide slightly modified by the very negative zeta potential provided by the thin polysiloxane layer $\left(2 \%\right.$ massic equivalent $\left.\mathrm{SiO}_{2}\right)$. Indeed, the isoelectric point (IEP) of the suspension was found at $\mathrm{pH} 10.5 \pm 1$, which is consistent with values measured for trivalent rare earth oxides (around 11) [20].

Finally, the sedimentation rate was measured since it provides invaluable information about the suspension stability and injectability. When suspension is placed in a test tube, particles gradually settle to the bottom. The sedimentation rate test measures the distance particles fall in a test tube in one hour and provides valuable information about colloidal stability and future behavior during syringe injections. The obtained suspension exhibits a sedimentation rate around 1-2\% after 1 hour and $10-15 \%$ after 24 hours. An ideal suspension is said to be in flocculation equilibrium, meaning that no clear supernatant is visible within the tubes. In our case, the values obtained were extremely low from a clinical point of view, considering that intracerebral injections are typically performed within 10-20 minutes during high-dose rate treatments [21]. Also, sedimentation rate of the same suspension was measured after one year storage following redispersion under moderate

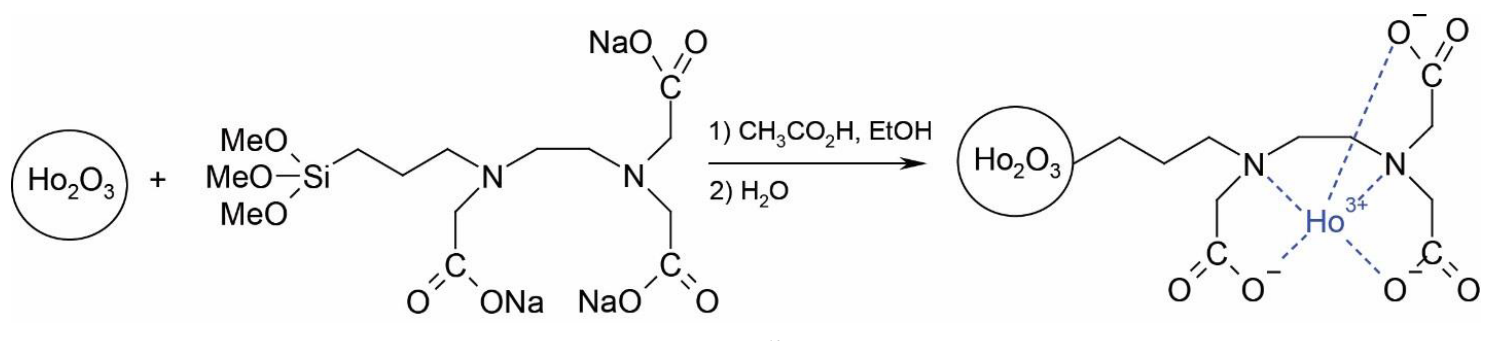

Figure 1: Synthesis scheme of ${ }^{165} \mathrm{Ho}$ polysiloxane particles. 
Citation: Marcon L, Gehan H, Khoshnevis M, Marmuse L, Carozzo C, et al. (2017) Synthesis of Highly-loaded Holmium-165 Siloxane Particles for Brachytherapy of Brain Cancer and Injectability Evaluation in Healthy Pig. J Nanomed Nanotechnol 8: 460. doi: 10.4172/2157-7439.1000460

Page 4 of 6

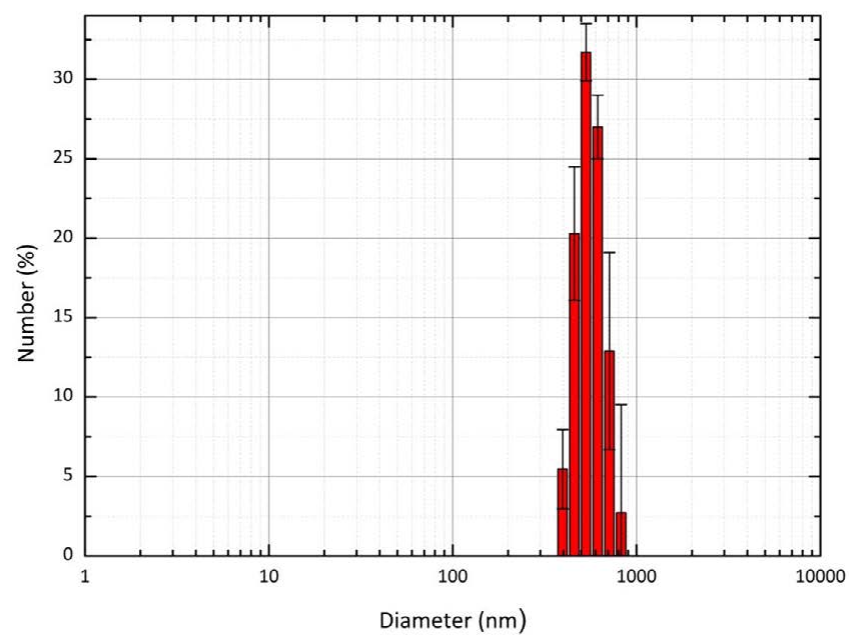

Figure 2: Averaged hydrodynamic diameter of ${ }^{165} \mathrm{Ho}$ polysiloxane particles. Each measurement consists of 6 runs.

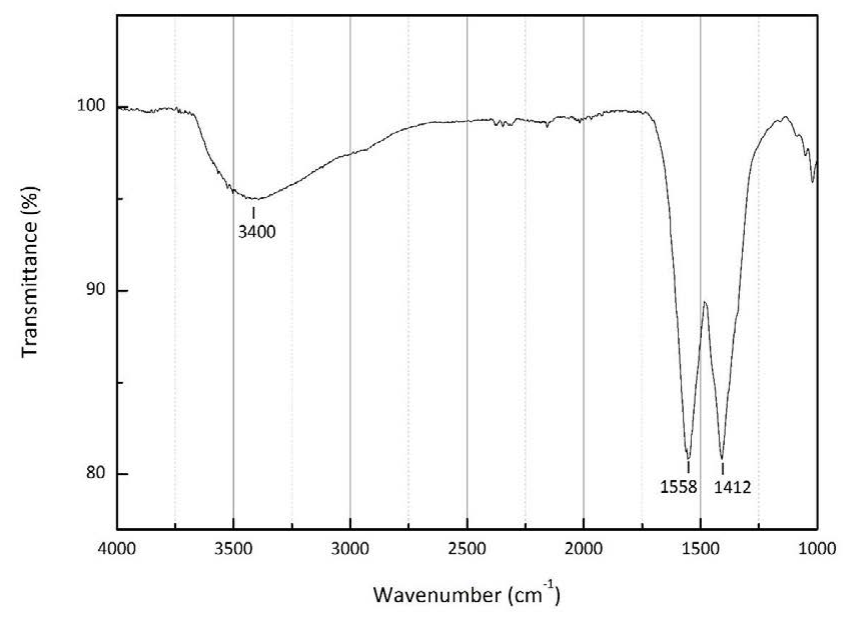

Figure 3: FTIR spectrum of the ${ }^{165} \mathrm{Ho}$ polysiloxane particles.

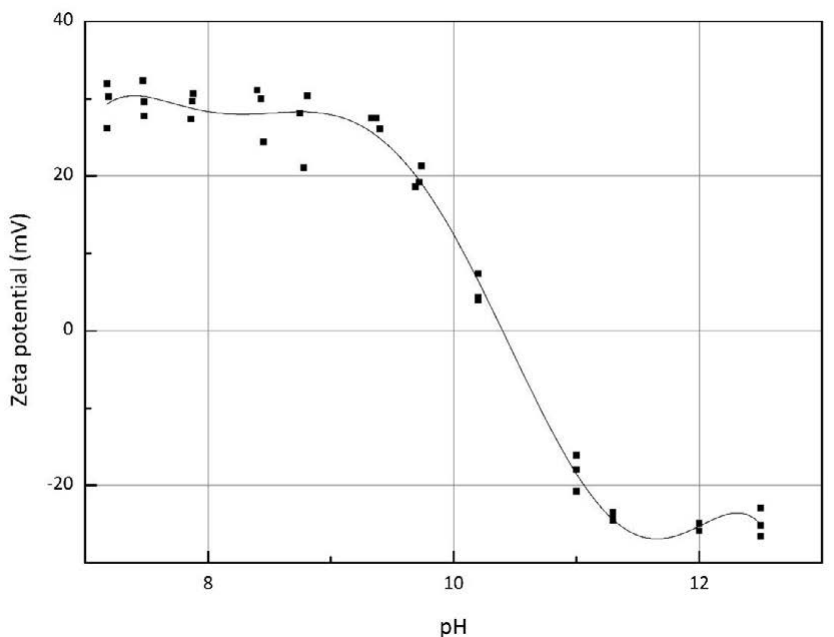

Figure 4: Variation in the zeta potential of the ${ }^{165} \mathrm{Ho}$ polysiloxane suspension in function of the $\mathrm{pH}$. vortex during 30 seconds and was unchanged. These results indicate that the suspension is easy to redisperse into a uniform mixture upon moderate shaking and keeps its stability.

Taken together, these data indicate that the suspension exhibits a high solid content that enhances its physical stability in water, making it $a$ priori suitable for brachytherapy of brain cancer.

\section{Stereotactic injection in the brain of a minipig}

Injectability, i.e. the performance of the formulation during injection [22], was then assessed in preclinical settings in the brain of a healthy pig. Yucatan minipig has been used as a relevant model to assess the injectability of the "cold" ${ }^{165}$ Ho siloxane suspension because of its similarities to humans in both structure and function $[23,24]$. For ethical concerns, only one animal was observed as a proof-of-concept. Various volumes ( 3,5 and $10 \mu \mathrm{L})$ of the suspension were injected in the brain of a minipig by coupling a stereotactic frame to a syringe pusher (Table 1). Injections were performed using either a metallic flexible cannula or a rigid needle pre-wetted with polyethylene glycol 400 (PEG 400). PEG 400 is a low-molecular-weight grade of polyethylene glycol widely used as a pre-wetting agent in a variety of pharmaceutical formulations due to its viscosity and low toxicity $[25,26]$. Also, blunt cannula has been included in the surgical procedure since practitioners increasingly use it over sharp needles due to its less traumatic shape. Injectability was subsequently assessed macroscopically and monitored by performing post-operative computerized tomography (CT) acquisitions.

The ideal suspension should be delivered to the site of interest in a controlled manner, be retained for a prolonged period of time and minimize reflux. In our case, suspension could be delivered successfully in the brain and no needle clogs were observed. A waiting time of two minutes was implemented following injection and the needle/cannula was then slowly removed from the brain in about $45 \mathrm{sec}$ to prevent reflux. However, a suspension volume of $1 \mu \mathrm{L}$ refluxed in the holes after the injection of 5 and $10 \mu \mathrm{L}$, both with needle and cannula. In contrast, no backflow was observed following injection of $3 \mu \mathrm{L}$. It turns out that a lower injection volume decreases the risk of reflux through the penetration tract.

In parallel, CT-Scan observations showed that the suspension (whatever the volume) is retained at the site of injection (Figure 5) although the slight reflux observed macroscopically is distinguishable.
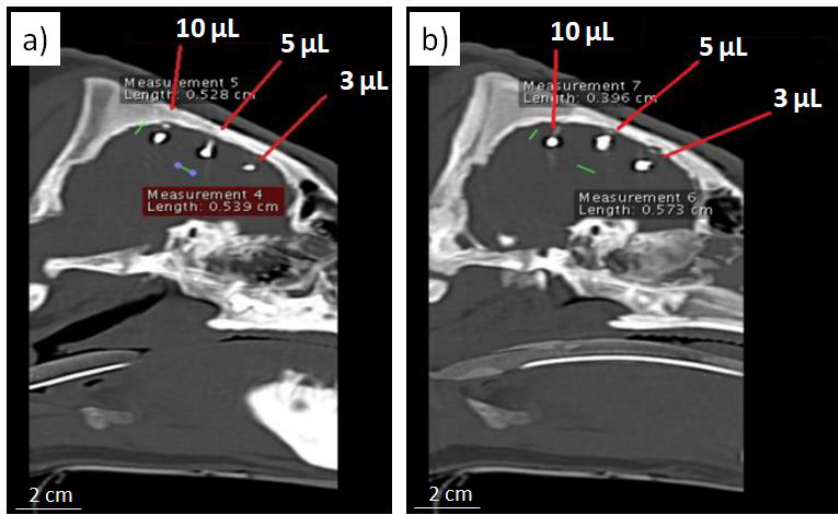

Figure 5: CT-Scan images after the injection of $3 \mu \mathrm{L}, 5 \mu \mathrm{L}$ and $10 \mu \mathrm{L}$ of suspension from cranial to caudal respectively use a) a needle (left hemisphere) and b) a cannula (right hemisphere). 
Citation: Marcon L, Gehan H, Khoshnevis M, Marmuse L, Carozzo C, et al. (2017) Synthesis of Highly-loaded Holmium-165 Siloxane Particles for Brachytherapy of Brain Cancer and Injectability Evaluation in Healthy Pig. J Nanomed Nanotechnol 8: 460. doi: 10.4172/2157-7439.1000460

Page 5 of 6

\begin{tabular}{|c|c|c|c|}
\hline Tube characteristics (Injection site) & Injected suspension volume ( $\mu \mathrm{L})$ & Refluxed volume $^{\dagger}(\mu \mathrm{L})$ & Distributed volume in brain tissue ${ }^{\ddagger}(\mu \mathrm{L})$ \\
\hline \multirow[t]{3}{*}{$25 \mathrm{G} \times 50 \mathrm{~mm}$ lumbar puncture needle (left hemisphere) } & 3 & l & 6 \\
\hline & 5 & $1 \mu \mathrm{L}$ & 19 \\
\hline & $10^{*}$ & $1 \mu \mathrm{L}$ & 16 \\
\hline \multirow[t]{3}{*}{$25 \mathrm{G} \times 40 \mathrm{~mm}$ cannula (right hemisphere) } & 3 & 1 & 16 \\
\hline & 5 & $1 \mu \mathrm{L}$ & 25 \\
\hline & $10^{*}$ & $1 \mu \mathrm{L}$ & 14 \\
\hline
\end{tabular}

*2 $\times 5 \mu \mathrm{L}$ with 2 minutes idle time

tVolumes estimated visually

拉stimated from the CT acquisitions

Table 1: Summary of injection parameters and experimental observations. Column 3: Refluxed volume as estimated visually. Column 4: Distributed volumes in brain tissues estimated from the CT acquisitions. Flow rate: $100 \mu \mathrm{L} / \mathrm{min}$. Injection depth between $10.8 \mathrm{~mm}$ and $13.4 \mathrm{~mm}$ from the surface of the skull.

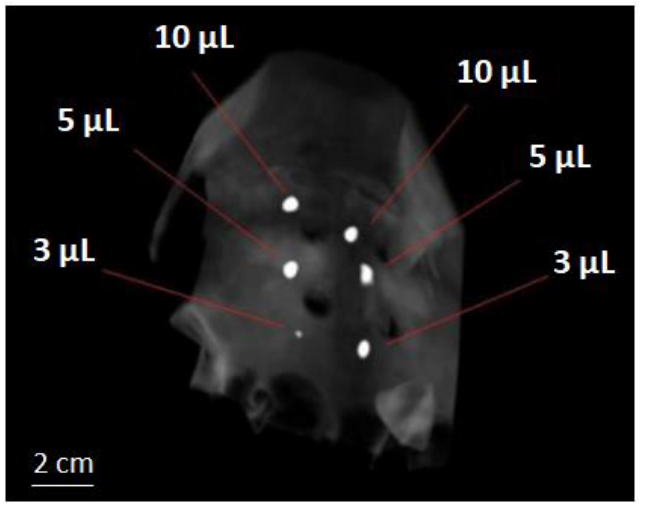

Figure 6: Three-dimensional (3D) CT-Scan images in caudo-ventral view after injection of the suspension. Left: Needle. Right: Cannula.

Three-dimensional volumes were then reconstructed using DICOM image viewers based on the post-operative CT acquisitions to track and estimate the volumes of distribution of the injected ${ }^{165} \mathrm{Ho}$ suspension in healthy brain tissue. The resulting image (Figure 6) enabled to estimate the reconstructed three-dimensional volumes (Table 1, last column). There is a difference in volume of $3 \mu \mathrm{L}$ injections between needle and cannula $(6 \mu \mathrm{L} v s .16 \mu \mathrm{L})$.

Interestingly, the distributed volumes after the injection of $10 \mu \mathrm{L}$ suspension are smaller than in the case of the injection of $5 \mu \mathrm{L}$ both in needle and cannula. This could be due to the additional idle time during the injection of $10 \mu \mathrm{L}$ suspension as $2 \times 5 \mu \mathrm{L}$ with 2 minutes idle time in between, meaning that 4 minutes in total for the injections of 10 $\mu \mathrm{L}$. It suggests that a longer post-injection waiting time would enable a better localization of the injected holmium suspension and would reduce the subsequent risk of reflux. However, this parameter will need to be adjusted in function of the clinical procedure (i.e. dosimetry, number of injections and idle time)

In addition to these results, it must be considered that permeability and elasticity of striatum tissue in healthy brain are different from those of tumoral tissue. In fact, the density of tumoral tissue is higher than healthy tissue and can potentially increase the risk of suspension backflow after intratumoral injections [27]. So, further tests using a pig xenograft model of brain cancer will be necessary 1) to get some insight about the reflux issue and 2) to circumvent it inside the tumor by adjusting needle's gauge, flow rate and injection pressure [28].

\section{Conclusions and Perspectives}

The suspension described previously can potentially enable the delivery of high ${ }^{166} \mathrm{Ho}$ concentration to the site of action via stereotactic injection. CT-Scan images following intracerebral injection of the suspension in a pig model showed that reflux issues may appear. However, this problem will be solved in future studies by decreasing the flow rate and the needle/cannula gauge. Next steps will consist in 1) evaluating the intratumoral injectability of cold holmium suspension and then 2) checking that the physicochemical properties of the suspension remain unchanged following the neutron activation of ${ }^{165} \mathrm{Ho}$ in ${ }^{166} \mathrm{Ho}$. These studies will also help to define the potential in vivo acute toxicity of the suspension.

\section{Acknowledgments}

This work was financially supported by the project TheraneaM "Therapy by Neutron Activation using Microparticles" ISI (Innovation Stratégique Industrielle).

\section{References}

1. Baba Al, Câtoi C, Baba Al (2007) Comparative oncology. The Publishing House of the Romanian Academ.

2. Buono S, Burgio N, Hamoudeh M, Fessi H, Hiltbr E, et al. (2007) Brachytherapy: State of the Art and Possible Improvements. Anticancer Agents Med Chem 7: 411-424.

3. Urbańska K, Sokołowska J, Szmidt M, Sysa P (2014) Glioblastoma multiformean overview. Współczesna Onkol 5: 307-312.

4. Stupp R, Mason WP, van den Bent MJ, Weller M, Fisher B, et al. (2005) Radiotherapy plus Concomitant and Adjuvant Temozolomide for Glioblastoma. N Engl J Med 352: 987-996.

5. http://www.strategyr.com/MarketResearch/Radiation_Therapy_Equipment Market_Trends.asp.

6. Gobitti C, Borsatti E, Arcicasa M, Roncadin M, Franchin G, et al. (2011) Treatment of recurrent high-grade gliomas with GliaSite brachytherapy: a prospective mono-institutional Italian experience. Tumori 97: 614-619.

7. Ruge MI, Kickingereder P, Grau S, Treuer S, Sturm V, et al. (2012) Stereotactic iodine-125 brachytherapy for brain tumors: temporary versus permanent implantation. Radiat Oncol 7: 94

8. Nijsen JF, van het Schip AD, Hennink WE, Rook DW, van Rijk PP, et al. (2002) Advances in nuclear oncology: microspheres for internal radionuclide therapy of liver tumours. Curr Med Chem 9: 73-82.

9. Vente MAD, Nijsen JFW, de Wit TC, Seppenwoolde JH, Krijger GC, et al. (2008) Clinical effects of transcatheter hepatic arterial embolization with holmium-166 poly(I-lactic acid) microspheres in healthy pigs. Eur J Nucl. Med Mol Imaging 35: 1259-1271.

10. Zielhuis SW, Nijsen JF, de Roos R, Krijger GC, van Rijk PP, et al. (2006 Production of GMP-grade radioactive holmium loaded poly(l-lactic acid) microspheres for clinical application. Int J Pharm 311: 69-74.

11. Zielhuis SW, Seppenwoolde JH, Bakker CJ, Jahnz U, Zonnenberg BA, et al. (2007) Characterization of holmium loaded alginate microspheres for multimodality imaging and therapeutic applications. J Biomed Mater Res A 82A: 892-898.

12. Kim JK, Han KH, Lee JT, Paik YH, Ahn SH, et al. (2006) Long-term Clinical Outcome of Phase Ilb Clinical Trial of Percutaneous Injection with Holmium-166/ 
Citation: Marcon L, Gehan H, Khoshnevis M, Marmuse L, Carozzo C, et al. (2017) Synthesis of Highly-loaded Holmium-165 Siloxane Particles for Brachytherapy of Brain Cancer and Injectability Evaluation in Healthy Pig. J Nanomed Nanotechnol 8: 460. doi: 10.4172/2157-7439.1000460

Page 6 of 6

Chitosan Complex (Milican) for the Treatment of Small Hepatocellular Carcinoma. Clin. Cancer Res 12: 543-548.

13. Bult W, Varkevisser R, Soulimani F, Seevinck PR, de Leeuw H, et al. (2010) Holmium Nanoparticles: Preparation and In Vitro Characterization of a New Device for Radioablation of Solid Malignancies. Pharm Res 27: 2205-2212.

14. Di Pasqua AJ, Yuan H, Chung Y, Kim JK, Huckle JE, et al. (2013) NeutronActivatable Holmium-Containing Mesoporous Silica Nanoparticles as a Potential Radionuclide Therapeutic Agent for Ovarian Cancer. J Nucl Med 54: 111-116

15. Claire Billotey (2009) Nouveaux agents de radiothérapie ciblée ou de curiethérapie à base d'oxydes et d'oxo-hydroxydes de terre rare.

16. Yaws CL (1995) Handbook of viscosity.

17. Mueller S, Llewellin EW, Mader HM (2010) The rheology of suspensions of solid particles. Proc R Soc Math Phys Eng Sci 466: 1201-1228.

18. van Driessche I, Hoste S (2006) In Functional Coatings.

19. Vallar S, Houivet D, El Fallah J, Kervadec D, Haussonne JM (1999) Oxide slurries stability and powders dispersion: optimization with zeta potential and rheological measurements. J Eur Ceram Soc 19: 1017-1021.

20. de Jong KP (2009) Synthesis of solid catalysts. Wiley Online Library.

21. Verhoeff JJC, Stalpers JLK, Coumou AW, Koedooder K, Lavini C, et al. (2007)
Experimental iodine-125 seed irradiation of intracerebral brain tumors in nude mice. Radiat Oncol 2: 38.

22. Cilurzo F, Selmin F, Minghetti $P$, Adami M, Bertoni E, et al. (2011) Injectability Evaluation: An Open Issue. AAPS Pharm Sci Tech 12: 604-609.

23. Kararli TT (1995) Comparison of the gastrointestinal anatomy, physiology, and biochemistry of humans and commonly used laboratory animals. Biopharm. Drug Dispos 16: 351-380.

24. Swindle MM, Smith AC, Hepburn BJ (1988) Swine as Models in Experimental Surgery. J Invest Surg 1: 65-79.

25. Gill HS, Prausnitz MR (2007) Coating Formulations for Microneedles. Pharm Res 24: 1369-1380.

26. Strickley RG (2004) Solubilizing Excipients in Oral and Injectable Formulations. Pharm Res 21: 201-230.

27. Pogoda K, Chin L, Georges PC, Byfield FJ, Bucki R, et al. (2014) Compression stiffening of brain and its effect on mechanosensing by glioma cells. New $J$ Phys 16: 075002.

28. Khoshnevis M, Carozzo C, Bonnefont-Rebeix C, Belluco S, Leveneur O, et al. (2017) Development of induced glioblastoma by implantation of a human xenograft in Yucatan minipig as a large animal model. J Neurosci Methods 282: 61-68. 